may perhaps be quoted: "Provisionally we are inclined to picture the lunar surface as very porous (photometric properties), all the details being covered by a thin layer of dust (polarimetry)", D. Barbier discusses the photometry of lunar eclipses, with special reference to properties of the Earth's upper atmo. sphere. Daniel L. Harris's chapter on the photometry and colorimetry of planets and satellites contains many hitherto unpublished measurements, made at the McDonald Observatory. There are two particularly good contributions by Audouin Dollfus, the first on polarization studies, the second on visual and photographic studies of planets at the Pic du Midi, which should lead to a wider appreciation of our debt to the author and his mentor, Bernard Lyot, who have greatly influenced present ideas about planetary surfaces and atmospheres. Edison Pettit describes early thermocouple measurements of planetary temperatures, and is followed by William $H$. Sinton on more recent radiometric work.

There are three chapters on radioastronomy. In the first, Cornell H. Mayer describes radio measure. ments in general, especially as they relate to thermal emission. Perhaps the most interesting result, now well known, is the high temperature, about $600^{\circ} \mathrm{K}$., shown by Venus at $10-\mathrm{cm}$. wave-length. The next two chapters, which might have been combined, are by B. F. Burke and Roger M. Gallet, respectively, both dealing with the intense bursts of radio emission from Jupiter, not yet fully understood. Milton L. Humason contributes a selection of planetary photographs taken with the 200-in. telescope and W. S. Finsen some interesting colour photographs of Mars. Although the illustrations are very good, I have the impression that there has been a perceptible loss of quality, probably unavoidable, in reproductions of planet photographs here and elsewhere in the book. The final chapter is by the senior editor, who winds up with an account of searches for intra-Mercurial planets and for new satellites.

The book is to be welcomed as a valuable addition to the rather sparse literature of this corner of astronomy. As in most collective works of this kind the articles do not appear to be all equally valuable, but their general standard is very satisfactory; half a dozen of them impressed me as unusually good. Editorial policy appears to have been to avoid subjects or theories which are pretty certain to change rapidly in the next few years. This may not suit the taste of some readers, but it ensures a longer useful life for the book.

R. O. REDMAN

\section{THE EARTH TODAY}

The Earth Today

Edited by A. H. Cook and T. F. Gaskell. (A collection of papers dedicated to Sir Harold Jeffreys by some of his students and colleagues on the occasion of his 70th birthday.) Pp. xi +404. (London: Royal Astronomical Society, 1961. Distributed by Oliver and Boyd, Ltd.). 80s. net.

was a happy idea of the Royal Astronomical Society to arrange a special issue of the Geophysical Journal, also available as a bound volume, containing papers by pupils and colleagues of Sir Harold Jeffreys in celebration of his seventieth birthday. The title appropriately recalls the four editions of Sir Harold's great work The Earth, which is a landmark in the application of mathematical methods to the solid
Earth. The papers are restricted to those on subjects which Sir Harold discusses in The Earth and therefore reflect the influence of his ideas. The first group of papers discusses the motion of satellites around the Earth and the consequent determination of the Earth's external gravitational field from observations of them. The next two groups deal with seismic body and surface waves. The fourth with the free oscillations of the Earth, the fifth with problems of heat conduction in the Earth. The two articles on the theory of the excitation of the Eulerian nutation and the Cromwell equatorial current and two on instruments complete the volume.

The volume, perhaps appropriately, respects Sir Harold's views on 'the Earth to-day'. Our planet is presented as being a perfectly elastic body, entirely non-magnetic, no drift of continents is allowable, and of course no convection in the mantle-silence hanging over the recent apostasy of oceanographers on the latter topic. Even Sir Edward Bullard, discussing heat-flow through the Atlantic Ocean, only hints at convection in the mantle. To maintain this static view of the Earth it is necessary to ignore some very important experimental results, and following Sir Harold's example in the fourth edition of The Earth, where the subject of palæomagnetism is refuted in two self-contradictory paragraphs, F. F. Evison explains away the rock magnetism data by a hypothesis which any field geologist could as simply refute as Dr. Samuel Johnson's famous rebuttal of Berkeley's philosophy. Or perhaps these critics of continental drift are believers who are following the precepts laid down by Cornfor in Micro-Cosmographica Academica, that ancient guide to academic politics, which advised those who wish to get new ideas accepted to argue weakly against their own side.

One may conclude, therefore, that while all geophysicists will wish to possess this valuable book, it would be a pity if anyone thought that it was in any real sense a survey of the growing points in geophysics to-day. Yet the subject has now reached a stage where it seems that the exciting hypotheses that the Earth has formed by accretion, the continents have drifted, the ocean floor has recently been formed and thermal convection is occurring in the mantle, can all be finally checked by new experimental methods.

S. K. RUNCORN

\section{EARLY MODELS OF THE UNIVERSE}

The Astronomical Works of Thabit B. Qurra By Francis J. Carmody. Pp. 262. (Berkeley and Los Angeles: University of California Press; London: Cambridge University Press, 1960.) 48s. net.

T)

R. CARMODY'S book is the first comprehensive collection that has ever been available to Western scholars of the works of the Arab astronomer Thabit ben Qurra. The work is not a translation; the author has reproduced principally, but not exclusively, the texts of Gerard of Cremona (1114-87), to whom we must always be indebted for the translation into mediæval Latin of much of the Arabic corpus of astronomy.

Thabit ben Qurra (Bencorath) was born about A.D. 836 at Harrân in Upper Mesopotamia. He became the leading member of a group of four trans- 